\title{
Paediatric distal radial fracture manipulation: multicentre analysis of process times
}

\author{
L Mitchell,' E Archer, ${ }^{,}$S Middleton, ${ }^{2}$ A Maclean, ${ }^{3}$ L Jones, ${ }^{1}$ J Benger, ${ }^{3}$ G Lloyd'
}

${ }^{1}$ Emergency Department, Royal Devon and Exeter Hospital, Exeter, UK; ${ }^{2}$ Emergency Department, Derriford Hospital, Plymouth, UK; ${ }^{3}$ Emergency Department, Bristol Children's Hospital, Bristol, UK

Correspondence to: Dr G Lloyd, Emergency Department, Royal Devon \& Exeter NHS Foundation Trust, Barrack Road, Exeter EX2 5DW, UK; gavin.lloyd@rdeft.nhs.uk

Accepted 3 April 2008

\section{ABSTRACT}

Background: Children with simple radial fractures requiring manipulation are conventionally admitted for manipulation under general anaesthesia. On the assumption that children (and their parents) wish to spend as little time in hospital as possible, a study was undertaken to explore the experience of children with distal radial fractures admitted for general anaesthesia.

Methods: A retrospective analysis was performed of the time taken from arrival at the emergency department (ED) to general anaesthesia and the time taken from arrival at the ED to hospital discharge in three centres in southwest England: the Bristol Children's Hospital, Derriford (Plymouth) Hospital and the Royal Devon \& Exeter Hospital.

Results: The median wait for general anaesthesia was $>8 \mathrm{~h}$ and the median wait from ED admission to discharge was $>21 \mathrm{~h}$. This compares with a typical arrival to discharge time for paediatric procedural sedation of 4-5 $\mathrm{h}$ in the ED of the Royal Devon \& Exeter Hospital. Conclusions: Given the assumption that children (and their parents) wish to spend as little time in hospital as possible, there appears to be a role for procedural sedation in the ED for this group of children, with a significantly reduced turnaround time anticipated.

Traditionally, children with distal forearm fractures needing manipulation are admitted for a general anaesthetic. There is some evidence that admission for surgery is traumatic to children and their parents, ${ }^{1}$ and that overnight admission can cause negative behavioural change. ${ }^{2}$ Admitting a child (and usually an accompanying parent) also causes disruption to the rest of the child's family and potential loss of earnings.

One of our departments (Royal Devon \& Exeter) has a typical arrival to discharge time for paediatric sedation (for all procedures) of 4-5 h. On the assumption that children (and their parents) wish to spend as little time in hospital as possible, we set out to explore the experience of children with distal radial fractures who are admitted for general anaesthesia.

Specifically we aimed to establish: (1) the time from arrival at the emergency department (ED) to general anaesthesia and (2) the time from arrival at the ED to hospital discharge.

\section{METHODS}

We retrospectively reviewed case notes for all children needing distal radial fracture manipulation under general anaesthesia over a 12-month period at the Bristol Children's Hospital, Derriford (Plymouth) Hospital and the Royal Devon and Exeter Hospital. The review dates were 1 January
2006-31 December 2006, 1 November 2005-31 October 2006 and 1 March 2005-28 February 2006, respectively. Standardised data collection forms were used or adapted to a spreadsheet version. Children with fractures not requiring manipulation or needing open reduction/fixation were excluded. Three clinicians working at the individual hospitals collected the raw data. This was collated and analysed by a fourth clinician to yield centre-specific and collective results. A person independent of the study verified the results.

\section{RESULTS}

Collectively, 147 children were identified of whom 133 (for ED arrival to time of general anaesthetic) and 109 (for ED arrival to discharge time) had data available for analysis (table 1).

\section{DISCUSSION}

Children with greenstick distal radial fractures needing manipulation wait a median time in excess of $8 \mathrm{~h}$ for a general anaesthetic and $21 \mathrm{~h}$ for hospital discharge. They would appear to wait longer for a general anaesthetic in a paediatric specialist hospital. We suggest this may be a consequence of loss of priority on the trauma list routinely given to children in general hospitals

Procedural sedation for these children in the ED is a reasonable solution. Ketamine, given either intravenously or intramuscularly, has a strong track record regarding safety and efficacy. ${ }^{3}{ }^{4}$ An evidencebased clinical policy for sedation in children has been established by the American College of Emergency Physicians (ACEM), ${ }^{5}$ and evidence-based guidelines by the Clinical Effectiveness Committee of the British Association for Emergency Medicine (BAEM) for the use of ketamine in the ED have been in existence since $2004 .^{6}$

\section{Limitations of the study}

This study is a retrospective chart/notes review so its findings are of limited validity; "medical records are informal diaries of observations, impressions, and hunches ... translation of these verbal descriptions into hard, quantitative data is fraught with error". Nevertheless, we transcribed rather than translated hard data; the time of arrival to the ED is accurately and automatically documented on ED records. The time of onset of general anaesthesia is documented routinely by the anaesthetist on the patient's anaesthetic chart, but is potentially inaccurate and was almost always rounded to the nearest $15 \mathrm{~min}$ in our dataset.

The data collectors were not blinded to the study hypothesis, were not specifically trained in data collection and there was no verification of 
Table 1 Median process times for hospitals individually and collectively

\begin{tabular}{lll}
\hline Hospital & $\begin{array}{l}\text { Arrival to time of general } \\
\text { anaesthetic (n) }\end{array}$ & $\begin{array}{l}\text { Arrival to time of discharge } \\
\text { (n) }\end{array}$ \\
\hline Exeter & $7 \mathrm{~h} 33 \mathrm{~min}(58)$ & $21 \mathrm{~h} 11 \mathrm{~min}(59)$ \\
Derriford & $6 \mathrm{~h} 0 \mathrm{~min}(52)$ & $21 \mathrm{~h} 52 \mathrm{~min}(39)$ \\
Bristol & $18 \mathrm{~h} 18 \mathrm{~min}(23)$ & $26 \mathrm{~h} 30 \mathrm{~min}(11)$ \\
Overall median & $8 \mathrm{~h} 14 \mathrm{~min}$ & $21 \mathrm{~h} 38 \mathrm{~min}$ \\
\hline
\end{tabular}

$\mathrm{n}$, number of cases with data available at each centre.

initial data generated from the notes. The time period for data collection was 1 year, but each centre used different start and finish dates, potentially biasing the result.

However, the data collected was simple and numerical and recorded directly by clinicians onto standardised data collection forms. The time elapsed before general anaesthesia and discharge, calculated from the raw data for both individual centres and collectively, was independently verified. The three hospitals studied are arguably collectively representative of most centres in the UK. We feel these factors strengthen the findings of the study.

\section{CONCLUSION}

In this three-centre study, children with a simple radial fracture requiring manipulation had a median wait of $8 \mathrm{~h}$ for a general anaesthetic and the median wait from ED admission to discharge was in excess of $21 \mathrm{~h}$. There appears to be a role for procedural sedation in the ED for these children. Significant reduction in turnaround times might be expected from this strategy, with evident benefit for the children and their families.

Acknowledgements: The authors thank Jason Smith for supervising the study in Plymouth.

\section{Competing interests: None.}

Contributions: LM collated and analysed the raw data and co-wrote the paper. EA, SM and AM collected the data from their respective emergency departments. LJ and $\mathrm{JB}$ advised and helped supervise the study; JB also edited the paper. GL had the original idea, supervised the study, co-wrote the paper and acts as guarantor.

\section{REFERENCES}

1. Ben AG, Kosov I, Reiss A, et al. Is elective surgery traumatic for children and their parents? J Paediatr Child Heath 2006;42:618-24.

2. Stargatt R, Davidson AJ, Huang GH, et al. A cohort study of the incidence and risk factors for negative behavior changes in children after general anaesthesia. Paediatr Anaesth 2006;16:846-59.

3. Sacchetti A, Stander E, Ferguson N, et al. Pediatric procedural sedation in the community emergency department: results from the ProSCED Registry. Pediatr Emerg Care 2007;23:218-222.

4. McGlone RG, Howes MC, Joshi M. The Lancaster experience of 2.0 to $2.5 \mathrm{mg} / \mathrm{kg}$ intramuscular ketamine for paediatric sedation: 501 cases and analysis. Emerg Med J 2004;21:290-5.

5. Mace SE, Barata IA, Cravero JP, et al. Clinical policy: evidence-based approach to pharmacologic agents used in pediatric sedation and analgesia in the emergency department. Ann Emerg Med 2004;44:342-77.

6. British Association for Emergency Medicine. Clinical Effectiveness Committee. Guideline for ketamine sedation in emergency departments. www.emergencymed.ac. uk/temp/1071 CEC-Ketamine-Sedation.pdf (accessed 9 Nov 2008).

7. Gilbert EH, Lowenstein SR, Koziol-McLain J, et al. Chart reviews in emergency medicine research: where are the methods? Ann Emerg Med 1996;27:305-8.

\section{Images in emergency medicine}

\section{Non-reducible hip dislocation in the ED}

A patient underwent a revision of total hip replacement for recurrent dislocation. Ten months later she sustained a further atraumatic dislocation of the prosthetic hip. After radiography in the emergency department (ED), she was sedated with propofol and reduction was attempted. The reduction failed despite good sedation and manipulation technique. The orthopaedic team took over her care and it was later recognised that she had been fitted with a constrained acetabular component that could only be reduced by an open method in theatre. This was clearly visible on the initial radiograph, indicated by the metal locking ring (fig 1). Failure to recognise this not uncommonly used device resulted in unnecessary procedures with their potential complications.

\section{Worth, ${ }^{1}$ A Harris ${ }^{2}$}

${ }^{1}$ Emergency Department, Plymouth Hospitals NHS Trust, Plymouth, Devon, UK;

${ }^{2}$ Emergency Department, Royal Devon and Exeter Foundation Trust, Exeter, Devon, UK

Correspondence to: Dr C Worth, Emergency Department, Plymouth Hospitals NHS Trust, Derriford Road, Crownhill, Plymouth, Devon PL6 8DH, UK; cassieworth@ hotmail.com

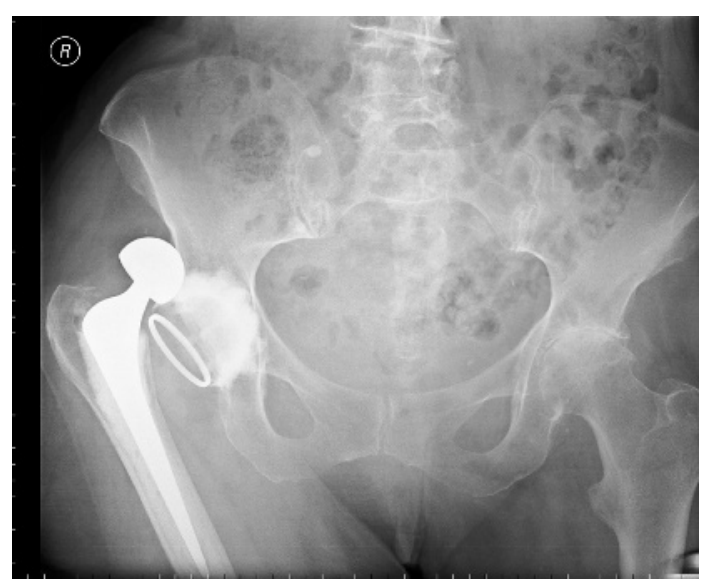

Figure 1 Radiograph with metal locking ring clearly visible.

Competing interests: None.

Patient consent: Obtained.

Emerg Med J 2009;26:42. doi:10.1136/emj.2008.058370

\section{REFERENCE}

1. Khan RJ, Fick D, Alakeson R. A constrained acetabular component for recurrent dislocation. J Bone Joint Surg (Br) 2006:88-B:870-6. 


\section{EMJ}

\section{Paediatric distal radial fracture manipulation: multicentre analysis of process times}

L Mitchell, E Archer, S Middleton, et al.

Emerg Med J 2009 26: 41-42

doi: $10.1136 / \mathrm{emj} .2007 .057208$

Updated information and services can be found at:

http://emj.bmj.com/content/26/1/41.full.html

These include:

References This article cites 6 articles, 1 of which can be accessed free at: http://emj.bmj.com/content/26/1/41.full.html\#ref-list-1

Email alerting Receive free email alerts when new articles cite this article. Sign up in service the box at the top right corner of the online article.

Topic Articles on similar topics can be found in the following collections

Collections

Fractures (206 articles)

Other anaesthesia (9078 articles)

Trauma (12806 articles)

Notes

To request permissions go to:

http://group.bmj.com/group/rights-licensing/permissions

To order reprints go to:

http://journals.bmj.com/cgi/reprintform

To subscribe to BMJ go to:

http://group.bmj.com/subscribe/ 